\title{
ANALISIS PENGARUH BANGUNAN, PERALATAN DAN SUMBER DAYA MANUSIA TERHADAP KEPUASAN PASIEN (Studi Kasus di Puskesmas Rawabuntu Serpong Tangsel)
}

\author{
Jakariah \\ dosen01225@unpam.ac.id
}

\begin{abstract}
ABSTRAK
Penelitian ini bertujuan untuk mengetahui berapa besar pengaruh bangunan, peralatan dan sumber daya manusia terhadap kepuasan pasien di Puskesmas Rawabuntu.

Populasi dalam penelitian ini adalah pengguna jasa pelayanan/ pasien berobat di puskesmas rawabuntu serpong tangerang selatan. Sampel yang digunakan dalam penelitian ini adalah sejumlah 55 responden, teknik pengambilan sampel ditentukan secara acak atau dikenal dengan teknik random sampling.Teknik analisis data yang digunakan adalah tes validitas dan reliabilitas, uji asumsi klasik, model regresi berganda, koefisiensi determinasi $\left(R^{2}\right)$, pengujian hipotesis dengan uji parsial (uji t) dan uji simultan (uji F) dengan taraf signifikan 5\% menggunakan program SPSS for Windows Version 17.

Berdasarkan hasil penelitian; Variabel banguna berpengaruh positif dan signifikan terhadap kepuasan pasien dengan nilai koefisien sebesar 0,409. Yang artinya jika variabel banguna meningkat satu satuan dengan asumsi variabel peralatan dan variabel sumber daya manusia tetap, maka Kepuasan pasien akan meningkat sebesar 0,409 . Variabel peralatan berpengaruh positif dan signifikan terhadap kepuasan pasien dengan nilai koefisien sebesar 0,129 . Yang artinya jika variabel peralatan meningkat satu satuan dengan asumsi variabel banguna dan variabel sumber daya manusia tetap, maka kepuasan pasien akan meningkat sebesar 0,129. Variabel Sumber daya manusia berpengaruh positif dan signifikan terhadap kepuasan pasien dengan nilai koefisien sebesar 0,779. Yang artinya jika variabel SDM meningkat satu satuan dengan asumsi variabel sumber daya manusia banguna dan variabel Peralatan tetap, maka kepuasan pasien akan meningkat sebesar 0,779. Faktor Banguna, Peralatan, dan Sumber daya manusia, secara bersama-sama mempunyai pengaruh positif yang signifikan terhadap Kepuasan pasien pada Puskesmas Rawabuntu. Model regresi berganda yang diperoleh adalah $Y=2.035+0,409 X_{1}+0,129 X_{2}+0,779 X_{3}$
\end{abstract}

Kata Kunci: Bangunan, Peralatan, Sumber Daya manusia dan Kepuasan Pasien

\section{ABSTRACT}

This study aims to determine how much influence buildings, equipment and human resources have on patient satisfaction at the Rawabuntu Health Center.

The population in this study were users of services / patients seeking treatment at the health center Rawabuntu Serpong, South Tangerang. The sample used in this study was 55 respondents, the sampling technique was determined randomly or known as the random sampling technique.The data analysis techniques used were validity and reliability tests, classic assumption tests, multiple regression models, coefficient of determination (R2), hypothesis testing with partial tests ( $t$ test) and simultaneous tests ( $F$ test) with a significant level of 5\% using the SPSS program for Windows Version 17.

Based on research results; The variable wakea has a positive and significant effect on patient satisfaction with a coefficient of 0.409. Which means if the building variable increases by one unit assuming the equipment variable and the human resource variable is fixed, then patient satisfaction will increase by 0.409. Equipment variables have a positive and significant effect on patient satisfaction with a coefficient of 0.129 . Which means that if the equipment variable increases by one unit with the construct variable assumption and the human resource variable remains, then patient satisfaction will increase by 0.129 . 
Variables Human resources have a positive and significant effect on patient satisfaction with a coefficient of 0.779 . Which means that if the $H R$ variable increases by one unit with the assumption that the human resource variable is variable and the equipment variable is fixed, then patient satisfaction will increase by 0.779. Banguna Factors, Equipment, and Human Resources, together have a significant positive effect on patient satisfaction at the Rawabuntu Health Center. The multiple regression model obtained is $Y=2,035+$ $0,409 \times 1+0,129 \times 2+0,779 \times 3$

Keywords: Buildings, Equipment, Human Resources and Patient Satisfaction

\section{A. Pendahuluan}

Untuk dapat memenuhi kebutuhan dan tuntutan tersebut, tidak ada upaya lain yang dapat dilakukan, kecuali menyelenggarakan pelayanan kesehatan yang sebaik-baiknya. Hakikat dasar dari rumah sakit/ Puskesmas adalah pemenuhan kebutuhan dan tuntutan pasien yang mengharapkan penyelesaian masalah kesehatan pada rumah sakit/ puskesmas yang mampu memberikan pelayanan medis sebagai upaya penyembuhan dan pemulihan atas rasa sakit yang dideritanya. Pasien mengharapkan pelayanan yang siap, cepat, tanggap dan nyaman terhadap keluhan penyakit pasien. Dalam mewujudkan kepuasan pasien tersebut pelayanan prima menjadi utama dalam pelayanan di Rumah Sakit/ Puskesmas.

Terciptanya kepuasan pasien tentunya akan melahirkan kepercayaan masyarakat terhadap puskesmas. Kepuasan pasien ini pada akhirnya dapat memberikan beberapa manfaat, di antaranya terjalinnya hubungan yang harmonis antara penyedia barang dan jasa dengan pelanggan. Pelayanan yang telah diterapkan di Puskesmas ini yaitu dengan memberikan senyum, salam, sapa, sopan dan santun (5 S) kepada setiap pasien yang datang berobat sehingga memberikan kesan yang akrab dan nyaman serta tidak menimbulkan rasa kekhawatiran bagi pasien terhadap penyakit yang diderita serta berusaha memberikan pengobatan yang terbaik terhadap penyakit pasien.

Dalam hal ini puskesmas Rawabuntu mempunyai keunggulan dalam mewujudkan kepuasan pasien diantarannya, yakni tersedianya bangunan yang baru dan strategis, peralatan yang cukup dan sumber daya manusia yang handal dan kompeten.

Berdasarkan latar belakang masalah yang ada maka penulis tertarik untuk mengadakan penelitian yang lebih jauh di Puskesmas tersebut, dan penulis memutuskan mengambil judul "Analisis Pengaruh Bangunan, Peralatan \& Sumber Daya Manusia terhadap Kepuasan Pasien" (Studi Kasus Puskesmas Rawabuntu Serpong Tangsel)".

\section{B. Perumusan Masalah}

Berdasarkan latar belakang masalah yang telah diuraikan diatas maka penulis merumuskan masalah sebagai berikut:

1. Apakah terdapat pengaruh positif dan signifikan antara bangunan gedung terhadap kepuasan pasien

2. Apakah terdapat pengaruh positif dan signifikan anatara peralatan medis, terhadap kepuasan pasien.

3. Apakah terdapat pengaruh positif dan signifikan antara sumber daya manusia, terhadap kepuasan pasien. 
4. Apakah terdapat pengaruh positif dan signifikan variabel bangunan, peralatan, dan sumber daya manusia secara bersama-sama terhadap kepuasan pasien

\section{Tujuan Penelitian}

Mengacu kepada perumusan masalah, penelitian ini bertujuan untuk menemukan bukti empiris atas hal-hal sebagai berikut:

1. Untuk mengetahui apakah variabel bangunan, peralatan dan sumber daya manusia berpengaruh positif dan signifikan terhadap kepuasan pasien.

2. Untuk mengetahui dari variabel bangunan, peralatan dan sumber daya manusia, variabel manakah yang paling berpengaruh dominan terhadap kepuasan pasien.

3. Seberapa besar pengaruh variabel $\mathrm{X} 1, \mathrm{X} 2$ dan $\mathrm{X} 3$ terhadap kepuasan pasien pada puskesmas Rawabuntu Serpong Kota Tangsel secara bersama-sama.

D. Landasan Teori

Pengertian Bangunan

Dalam pasal 1 poin 1 UU No. 28 tahun 2002 tentang Bangunan Gedung, memuat pengertian apa yang dimaksud dengan bangunan gedung; Bangunan gedung adalah wujud fisik hasil pekerjaan konstruksi yang menyatu dengan tempat kedudukannya, sebagian atau keseluruhannya berada diatas dan / atau berada di dalam tanah dan / atau air, yang berfungsi sebagai tempat manusia melakukan kegiatannya, baik untuk hunian atau tempat tinggal, kegiatan agama, kegiatan usaha, kegiatan sosial, budaya maupun kegiatan khusus".

\section{Definisi Alat Kesehatan}

Menurut peraturan Mentri kesehatan RI. No. 220/Men.Kes/Per/IX/1976 tertanggal 6 september 1976, yang dimaksud dengan: ALAT KESEHATAN (ALKES) adalah barang, instrument, atau alat termasuk tiap komponen, bagian atau perlengkapannaya yang diproduksi, dijual atau dimaksudkan untuk digunakan dalam : pemeliharaan dan perawatan kesehatan, diagnos, penyembuhan, peringanan atau pencegahan penyakit, kelainan keadaan badan atau gejalanya pada manusia. Pemulihan, perbaikan atau perubahan suatu fungsi badan atau struktur badan manusia. Diagnose kehamilan pada manusia atau pemeliharaan selama hamil dan setelah melahirkan termasuk pemeliharaan bayi.

\section{Definisi Sumber Daya Manusia}

Menurut Nawawi (2001) ada tiga pengertian sumber daya manusia yaitu : Pertama, Sumber daya manusia adalah manusia yang bekerja dilingkungan suatu organisasi (disebut juga personil, tenaga kerja, pekerja atau karyawan). Kedua, Sumber daya manusia adalah potensi manusiawi sebagai penggerak organisasi dalam mewujudkan eksistensinya. Ketiga, Sumber daya manusia adalah potensi yang merupakan aset dan berfungsi sebagai modal (non material/non finansial) di dalam organisasi bisnis, yang dapat mewujudkan 
menjadi potensi nyata (real) secara fisik dan non-fisik dalam mewujudkan eksistensi organisasi.

Pengertian Kepuasan Pasien

Menurut Philip Kotler (2002:42), kepuasan adalah "perasaan senang atau kecewa seseorang yang muncul setelah membandingkan antara persepsi atau kesannya terhadap kinerja suatu produk dan harapanharapannya".

\section{Kerangka Pemikiran}

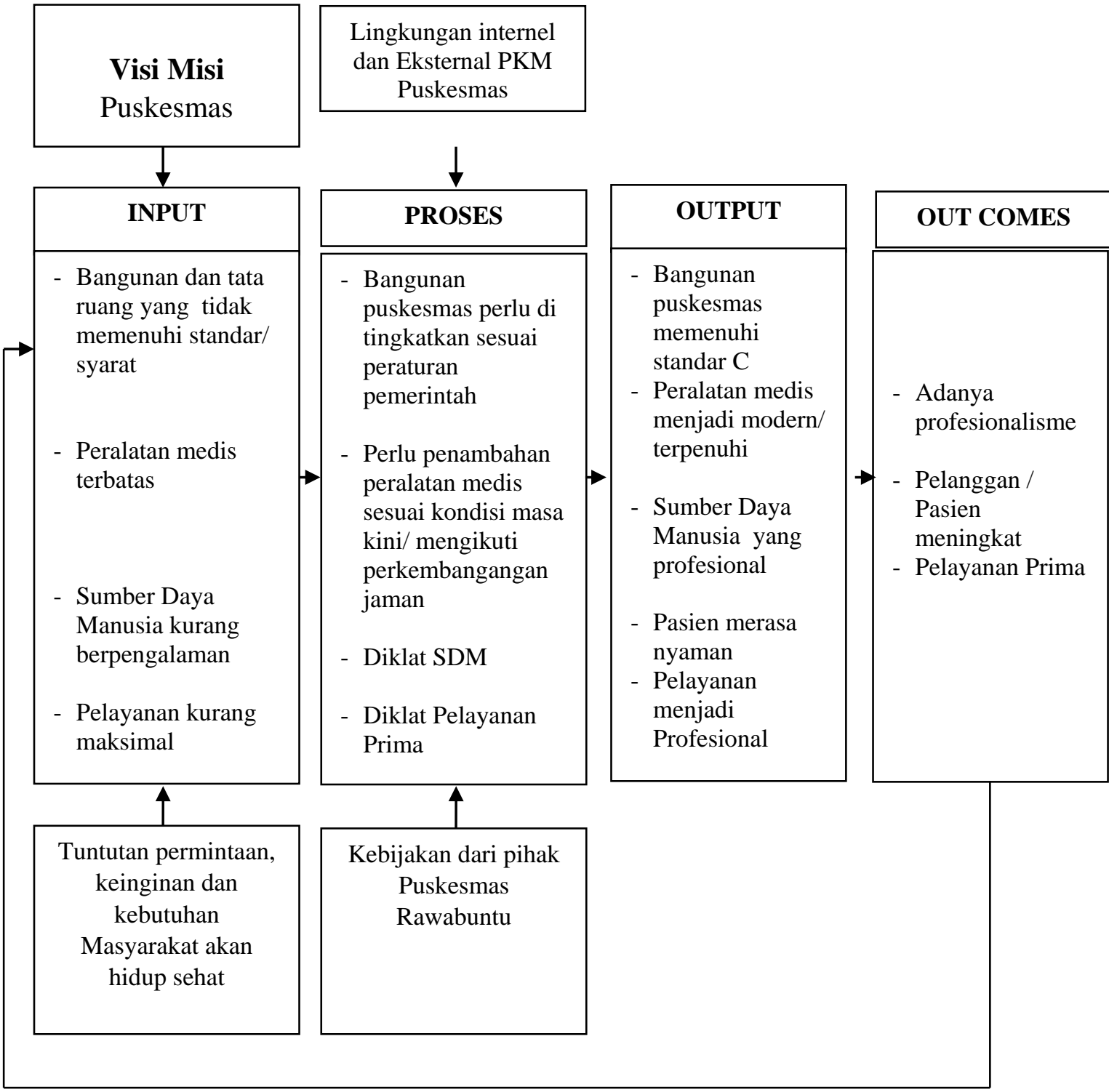

Umpan Balik

Gambar : 2.1 Kerangka Pemikiran 


\section{Hipotesis Penelitian}

Hipotesis adalah suatu perumusan sementara mengenai suatu hal yang dibuat untuk menjelaskan hal itu dan juga dapat menuntun atau menyarankan penyelidikan selanjutnya (Husein, 2003), berdasarkan definisi tersebut maka perumusan hipotesis dalam penelitian ini adalah sebagai berikut:

1. Diduga terdapat pengaruh yang positif dan signifikan dari Bangunan terhadap kepuasan konsumen

2. Diduga terdapat pengaruh positif dan signifikan dari Peralatan terhadap kepuasan konsumen.

3. Diduga terdapat pengaruh positif dan signifikan dari Sumber daya manusia terhadap kepuasan konsumen.

Diduga terdapat pengaruh positif dan signifikan variabel bangunan, peralatan, dan sumber daya manusia secara bersama-sama terhadap kepuasan pasien.

\section{E. METODOLOGI PENELITIAN}

Lokasi penelitian dilakukan secara sengaja (purposive) di Puskesmas Rawa Buntu Serpong Kota Tangerang Selatan. Adapun waktu yang diperlukan untuk melakukan penelitian ini ialah dari bulan Februari 2016 sampai dengan bulan Mei 2016.

Penelitian yang dilakukan ini bersifat korelasional dimana penelitian tersebut mempelajari dua hubungan variabel atau lebih, dan bagaimana variabel - variabel dinyatakan dalam satui nndeks yang dinamakan koefisien korelasi.

Dalam penelitian ini tidak seluruh populasi yang diambil, mengingat jumlah yang banyak dan belum tentu diketahui secara pasti. Oleh karena itu dalam penelitian ini digunakan sampel, yaitu sebagian dari jumlah dan karakteristik yang dimiliki oleh populasi tersebut. Sampel pada penelitian ini adalah sebesar 55 oarang responden.

\section{Metode Analisis Data}

Metode analisis data yang digunakan dalam penelitian ini adalah;

1. Analisis Kuantitatif, adalah suatu bentuk analisis yang penyajiannya dalam angka-angka yang dapat diukur dan dihitung.

2. Uji Validitas, pengujian validitas data digunakan untuk mengukur sah atau valid tidaknya suatu kuesioner.

3. Uji Reliabilitas, adalah pengukuran untuk suatu gejala.

4. Data Asumsi Klasik, uji asumsi klasik terhadap model regresi yang digunakan, dilakukan agar dapat diketahui apakah model regresi tersebut merupakan model regresi yang baik atau tidak (Ghozali, 2001)

5. Uji Multikolinieritas, uji multikolinieritas dilakukan untuk menguji apakah pada model regresi ditemukan adanya korelasi antar variabel bebas.

6. Uji heteroskedastisitas, uji heteroskedastisitas diklakukan untuk menguji apakah dalam sebuah model regresi terjadi ketidaksamaan varians residual dari satu pengamatan ke pengamatan yang lain tetap, maka disebut heteroskedastisitas (Ghozali, 2001).

7. Uji Normalitas, tujuan uji normalitas adalah untuk menguji apakah dalam sebuah model regresi, variabel terikat dan variabel bebas atau keduanya mempunyai distribusi normal ataukah tidak. 
8. Uji koefisien Regresi Linear Berganda; Pertama Uji t, digunakan untuk menguji berarti atau tidaknya hubungan variabel-variabel independen bangunan (X1), Peralatan (X2), sumber daya manusia (X3), dengan variabel dependen kepuasan pasien (Y). Kedua Uji F (Uji simultan), digunakan untuk mengetahui hubungan antara variabel independent dan varibel dependent, apakah bangunan, peralatan dan sumber daya manusia, benar-benar berpengaruh secara simultan (bersama-sama) terhadap variabel Y (kepuasan pasien). (Ghozali, 2005).

9. Koefisien Determinasi, Koefisien determinasi dilakukan untuk melihat adanya hubungan yang sempurna atau tidak, yang ditunjukkan pada perubahan variabel bebas dan variabel terikat pada proporsi yang sama.

10. Analisis Regresi Linear Berganda, Analisis regresi berganda digunakan untuk mengetahhui seberapa besar pengaruh hubungan variabel bebas dan variabel terikat.

\section{F. HASIL DAN PEMBAHASAN}

\section{Hasil Uji validitas}

Berdasarkan perhitungan dengan menggunakan Sofware IBM SPSS (Statistical Program fof social science) versi 17, for windows. Seluruh butir pertanyaan yang digunakan dalam penelitian ini rhitung lebih besar nilai rtabel dan nilai rtabel dan nilai $r$ positif untuk variabel $X 1, X 2, \& X 3$, dan variabel $Y$ maka semua butir pertanyaan dikatakan valid.

Tabel 4.1 Hasil Uji Validitas

Uji Validitas Variabel Bangunan $\left(X_{1}\right)$

\begin{tabular}{|c|l|r|r|c|}
\hline No & Pertanyaan & $\begin{array}{c}\text { Nilai } \mathbf{r} \\
\text { hitung }\end{array}$ & $\begin{array}{c}\text { Nilai } \mathbf{r} \\
\text { tabel }\end{array}$ & Keterangan \\
\hline 1 & Kuesioner1 & 0,342 & 0,266 & Valid \\
\hline 2 & Kuesioner2 & 0,449 & 0,266 & Valid \\
\hline 3 & Kuesioner3 & 0,388 & 0,266 & Valid \\
\hline 4 & Kuesioner4 & 0,271 & 0,266 & Valid \\
\hline 5 & Kuesioner5 & 0,282 & 0,266 & Valid \\
\hline 6 & Kuesioner6 & 0,467 & 0,266 & Valid \\
\hline 7 & Kuesioner7 & 0,339 & 0,266 & Valid \\
\hline 8 & Kuesioner8 & 0,307 & 0,266 & Valid \\
\hline 9 & Kuesioner9 & 0,417 & 0,266 & Valid \\
\hline 10 & Kuesioner10 & 0,619 & 0,266 & Valid \\
\hline 11 & Kuesioner11 & 0,535 & 0,266 & Valid \\
\hline 12 & Kuesioner12 & 0,590 & 0,266 & Valid \\
\hline
\end{tabular}

Sumber: data primer yang diolah 
Tabel 4.2 Hasil Uji Validitas

Uji Validitas Variabel Peralatan $\left(\mathrm{X}_{2}\right)$

\begin{tabular}{|c|c|c|c|c|}
\hline No & Pertanyaan & $\begin{array}{c}\text { Nilai } \mathbf{r} \\
\text { hitung }\end{array}$ & $\begin{array}{c}\text { Nilai } \mathbf{r} \\
\text { tabel }\end{array}$ & Keterangan \\
\hline 1 & Kuesioner 1 & 0,325 & 0,266 & Valid \\
\hline 2 & Kuesioner 2 & 0,396 & 0,266 & Valid \\
\hline 3 & Kuesioner 3 & 0,430 & 0,266 & Valid \\
\hline 4 & Kuesioner 4 & 0,604 & 0,266 & Valid \\
\hline 5 & Kuesioner 5 & 0,528 & 0,266 & Valid \\
\hline 6 & Kuesioner 6 & 0,293 & 0,266 & Valid \\
\hline 7 & Kuesioner 7 & 0,716 & 0,266 & Valid \\
\hline 8 & Kuesioner 8 & 0,532 & 0,266 & Valid \\
\hline 9 & Kuesioner 9 & 0,297 & 0,266 & Valid \\
\hline 10 & Kuesioner 10 & 0,406 & 0,266 & Valid \\
\hline
\end{tabular}

Sumber: Data praimer yang diolah

Tabel 4.3 Hasil Uji Validitas

Uji Validitas Variabel SDM $\left(\mathrm{X}_{3}\right)$

\begin{tabular}{|c|c|c|c|c|}
\hline No & Pertanyaan & $\begin{array}{c}\text { Nilai } \mathbf{r} \\
\text { Hitung }\end{array}$ & Nilai $\mathbf{r}$ Tabel & Keterangan \\
\hline 1 & Kuesioner1 & 0,412 & 0,266 & Valid \\
\hline 2 & Kuesioner2 & 0,392 & 0,266 & Valid \\
\hline 3 & Kuesioner3 & 0,550 & 0,266 & Valid \\
\hline 4 & Kuesioner4 & 0,400 & 0,266 & Valid \\
\hline 5 & Kuesioner5 & 0,538 & 0,266 & Valid \\
\hline 6 & Kuesioner6 & 0,657 & 0,266 & Valid \\
\hline 7 & Kuesioner7 & 0,660 & 0,266 & Valid \\
\hline 8 & Kuesioner8 & 0,652 & 0,266 & Valid \\
\hline 9 & Kuesioner9 & 0,493 & 0,266 & Valid \\
\hline 10 & Kuesioner10 & 0,607 & 0,266 & Valid \\
\hline 11 & Kuesioner11 & 0,430 & 0,266 & Valid \\
\hline
\end{tabular}

Sumber : Data primer yang diolah 
Tabel 4.4 Hasil Uji Validitas

Uji Validitas Variabel kepuasan Pasien (Y)

\begin{tabular}{|c|c|c|c|c|}
\hline No & Pertanyaan & $\begin{array}{c}\text { Nilai } \mathbf{r} \\
\text { hitung }\end{array}$ & $\begin{array}{c}\text { Nilai } \mathbf{r} \\
\text { tabel }\end{array}$ & Keterangan \\
\hline 1 & Kuesioner1 & 0,578 & 0,266 & Valid \\
\hline 2 & Kuesioner2 & 0,564 & 0,266 & Valid \\
\hline 3 & Kuesioner3 & 0,438 & 0,266 & Valid \\
\hline 4 & Kuesioner4 & 0,785 & 0,266 & Valid \\
\hline 5 & Kuesioner5 & 0,598 & 0,266 & Valid \\
\hline 6 & Kuesioner6 & 0,755 & 0,266 & Valid \\
\hline 7 & Kuesioner7 & 0,709 & 0,266 & Valid \\
\hline 8 & Kuesioner8 & 0,855 & 0,266 & Valid \\
\hline 9 & Kuesioner9 & 0,787 & 0,266 & Valid \\
\hline 10 & Kuesioner10 & 0,771 & 0,266 & Valid \\
\hline 11 & Kuesioner11 & 0,325 & 0,266 & Valid \\
\hline
\end{tabular}

Sumber : Data Primer yang diolah

Hasil perhitungan uji validitas sebagaimana tabel 4.8 diatas, menunjukan bahwa semua nilai $r_{\text {hitung }}$ lebih besar dari nilai $r_{\text {tabel }}(0,3)$ Sugiyono (2013:182). Oleh karena itu, dapat disimpulkan bahwa item dalam angket penelitian ini valid sehingga dapat digunakan sebagai instrument penelitian.

\section{Hasil Uji Reliabilitas}

Adapun hasil uji reabiliata untuk semua variabel dalam penelitian ini dapat dilihat pada tabel berikut :

Tabel 4.5 Uji Reabilitas

\begin{tabular}{|c|c|c|c|c|}
\hline No & Variabel & $\begin{array}{c}\text { Cronbach } \\
\text { Alpha }\end{array}$ & Nilai $\boldsymbol{r}$ tabel & Keterangan \\
\hline 1 & Bangunan & 0.579 & 0,266 & Reliabel \\
\hline 2 & Peralatan & 0.600 & 0,266 & Reliabel \\
\hline 3 & SDM & 0.737 & 0,266 & Reliabel \\
\hline 4 & $\begin{array}{c}\text { Kepuasan } \\
\text { Pasien }\end{array}$ & 0.868 & 0,266 & Reliabel \\
\hline
\end{tabular}

Sumber: Data primer yang diolah 
3. Uji Asumsi Klasik a. Uji Normalitas Data

Tabel 4.6 Hasil Uji Normalitas Data

One-Sample Kolmogorov-Smirnov Test

\begin{tabular}{|lr|r|}
\hline & & Unstandardized Residual \\
\hline Normal Parameters ${ }^{a, b}$ & .1728 & 55 \\
& .20622 & .1728 \\
Most Extreme Differences & .213 & .26842604 \\
& .213 & .213 \\
& -.206 & .213 \\
Kolmogorov-Smirnov Z & & -.206 \\
Asymp. Sig. (2-tailed) & & 1.583 \\
\hline
\end{tabular}

a. Test distribution is Normal

b. Calculated from data

Sumber : Data Primer yang telah diolah

Dari hasil pengujian diatas diperoleh nilai signifikansi sebesar $0.013>0,05$ maka asumsi normalitas terpenuhi.

\section{b. Uji Multikolinieritas}

Tabel 4.7 Hasil Uji Multikolinieritas

\section{Coefficients $^{a}$}

\begin{tabular}{|c|c|c|c|c|c|c|c|}
\hline \multirow[b]{2}{*}{ Model } & \multicolumn{2}{|c|}{$\begin{array}{l}\text { Unstandartdized } \\
\text { Coefficients }\end{array}$} & \multirow{2}{*}{\begin{tabular}{|c|}
$\begin{array}{c}\text { Standardiz } \\
\text { ed } \\
\text { Coefficient } \\
\text { s }\end{array}$ \\
Beta \\
\end{tabular}} & \multirow[b]{2}{*}{$t$} & \multirow[b]{2}{*}{ Sig. } & \multicolumn{2}{|c|}{ Collinearity Statistics } \\
\hline & B & $\begin{array}{l}\text { Std. } \\
\text { Error }\end{array}$ & & & & Telerance & VIF \\
\hline (Constant) & .302 & .705 & & .429 & .670 & & \\
\hline $\mathrm{X} 1$ & -.016 & .157 & -.011 & -.100 & .921 & .764 & 1.308 \\
\hline $\mathrm{X} 2$ & .120 & .161 & .091 & .744 & .461 & .675 & 1.483 \\
\hline X3 & .832 & .135 & .664 & 6.183 & .000 & .865 & 1.156 \\
\hline
\end{tabular}

Sumber : Data primer yang telah diolah

abel diatas dapat diketahui bahwa syarat untuk lolos dari uji multikolinearitas sudah terpenuhi oleh seluruh variabel independen yang ada, yaitu nilai tolerance yang tidak kurang dari 0,10 dan nilai VIF (Variance Inflation Factor) yang tidak lebih dari 10. Maka dari itu dapat di simpulkan bahwa seluruh variabel independen yang digunakan dalam penelitian ini tidak berkorelasi antara variabel independen satu dengan variabel independen lainnya. 


\section{c. Uji Heteroskedastisitas}

Hasil output SPSS diperoleh interpretasi (pada baris terakhir atau kolom terakhir).

Tabel 4.9 Heteroskedastisitas

\begin{tabular}{|c|c|c|c|}
\hline Variabel Bebas & $\mathbf{r}$ & Sig & Keterangan \\
\hline Bangunan (X1) & -0.265 & 0.051 & Hemokedastitas \\
Peralatan (X2) & --0.276 & 0.041 & Hemokedastitas \\
SDM (X3) & $-0-.380$ & 0.004 & Hemokedastitas \\
\hline
\end{tabular}

Sumber : Data Primer yang telah diolah.

Dari tabel diatas menunjukkan bahwa variabel yang diuji tidak mengandung heteroskedastisitas atau homoskedastisitas. Artinya tidak ada korelasi antara besarnya data dengan residual sehingga bila data diperbesar tidak menyebabkan residual (kesalahan) semakin besar pula.

\section{Analisis Regresi Linier Berganda}

Berdasarkan perhitungan regresi berganda menggunakan program IBM SPSS (Stasistical Program for Social Science) versi 17,00 for windows, diperoleh hasil sebagai berikut :

Tabel 4.10 Hasil Uji Regresi Berganda

\section{Coefficients $^{\mathrm{a}}$}

\begin{tabular}{|c|c|c|c|c|c|c|c|c|c|}
\hline \multirow[b]{2}{*}{ Model } & \multicolumn{2}{|c|}{$\begin{array}{c}\text { Unstandardize } \\
\text { d } \\
\text { Coefficients }\end{array}$} & \multirow{2}{*}{\begin{tabular}{|c|}
$\begin{array}{c}\text { Unstandardi } \\
\text { zed } \\
\text { Coefficients }\end{array}$ \\
Beta
\end{tabular}} & \multirow[b]{2}{*}{$t$} & \multirow[b]{2}{*}{ Sig } & \multicolumn{2}{|c|}{$\begin{array}{c}95,0 \% \\
\text { Confidence } \\
\text { Interval for B }\end{array}$} & \multicolumn{2}{|c|}{$\begin{array}{c}\text { Collinearity } \\
\text { Statistics }\end{array}$} \\
\hline & $B$ & $\begin{array}{l}\text { Std. } \\
\text { Error }\end{array}$ & & & & $\begin{array}{l}\text { Lower } \\
\text { Bound }\end{array}$ & $\begin{array}{l}\text { Upper } \\
\text { Bound }\end{array}$ & $\begin{array}{l}\text { Toler } \\
\text { ance }\end{array}$ & VIF \\
\hline $\begin{array}{l}1 \text { (Constan } \\
\text { t) }\end{array}$ & .302 & .705 & & .429 & .670 & -1.114 & 1.718 & & \\
\hline $\mathrm{X} 1$ & -.016 & .157 & -.011 & -.100 & .921 & -.331 & .300 & .764 & 1.308 \\
\hline$X 2$ & .120 & .161 & .091 & .744 & .461 & -.203 & .442 & .675 & 1.483 \\
\hline X3 & .832 & .135 & .664 & 6.183 & .000 & .562 & 1.102 & .865 & 1.156 \\
\hline
\end{tabular}

a. Dependent Variable: $Y$

Sumber : Data primer yang telah diolah

Dari hasil perhitungan pada tabel diatas dapat disajikan ke dalam bentuk persamaan regresi standardized sebagai berikut :

$Y=0,302+0,016 \times 1+0,120 \times 2+0,832 X 3$

Keterangan: 
$\mathbf{Y}=$ Kepuasan Pasien, $\mathbf{X 1}=$ Variabel Bangunan, $\mathbf{X 2}=$ Variabel Peralatan dan,

X3 = Variabel SDM

Hasil persamaan regresi berganda tersebut dapat dilihat bahwa koefisien regresi yang diperoleh bertanda positif. Hal tersebut menunjukkan bahwa variabel Bangunan, Peralatan dan SDM mempunyai pengaruh positif terhadap Kepuasan pasien, artinya setiap ada peningkatan variabel Bangunan, Peralatan dan SDM akan meningkatkan pula kepusan pasien untuk berobat pada Puskesmas Rawabuntu.

\section{Uji Hipotesis Parsial (Uji T)}

Untuk menguji pengaruh Bangunan, Peralatan, dan SDM secara parsial terhadap Kepuasan Pasien pada Puskesmas Rawabuntu, dapat digunakan dengan uji statistic $t(u j i t)$. Dengan menggunakan taraf signifikansi $5 \%(0,05)$ dan derajat kebesaran $(\mathrm{dk})$ dengan rumus : $\mathrm{dk}=\mathrm{n}$ $\mathrm{k}-1$, dimana $: n$ adalah jumlah responden dan $k$ adalah jumlah variabel yang diteliti.

Adapun hasil uji t dengan pengolahan IBM SPSS versi 17 for windows dapat dilihat pada tabel dibawah ini:

Tabel 4.11 Hasil Uji t

Coefficients $^{\mathrm{a}}$

\begin{tabular}{|c|c|c|c|c|c|c|c|c|c|c|}
\hline \multirow[t]{2}{*}{ Model } & \multicolumn{2}{|c|}{$\begin{array}{l}\text { Unstandardize } \\
\text { d Coefficients }\end{array}$} & \multirow{2}{*}{$\begin{array}{c}\begin{array}{c}\text { Standard } \\
\text { ized } \\
\text { Coefficie } \\
\text { nts }\end{array} \\
\text { Beta }\end{array}$} & \multirow[t]{2}{*}{$t$} & \multirow[t]{2}{*}{ Sig } & \multicolumn{2}{|c|}{$\begin{array}{c}95.0 \% \\
\text { Confidence } \\
\text { Interval for B }\end{array}$} & \multicolumn{3}{|c|}{ Correlations } \\
\hline & B & Std. Error & & & & $\begin{array}{l}\text { Lower } \\
\text { Bound }\end{array}$ & $\begin{array}{l}\text { Upper } \\
\text { Bound }\end{array}$ & $\begin{array}{l}\text { Zero- } \\
\text { order }\end{array}$ & $\begin{array}{l}\text { Parti } \\
\text { al }\end{array}$ & Part \\
\hline $\begin{array}{ll}1 & \text { (Constan } \\
\mathrm{t})\end{array}$ & $\begin{array}{c}2.03 \\
5\end{array}$ & .637 & & 3.196 & $\begin{array}{c}.00 \\
2\end{array}$ & .767 & 3.303 & & & \\
\hline $\begin{array}{l}\text { Banguna } \\
\mathrm{n}\end{array}$ & .409 & .155 & .230 & 2.632 & $\begin{array}{c}.00 \\
1\end{array}$ & .718 & .099 & .025 & .289 & .190 \\
\hline Peralatan & .129 & .173 & .065 & 1.746 & $\begin{array}{c}.04 \\
5\end{array}$ & -.216 & .475 & .074 & .085 & .054 \\
\hline SDM & .779 & .073 & .790 & $\begin{array}{c}10.67 \\
7\end{array}$ & $\begin{array}{c}.00 \\
0\end{array}$ & .633 & .924 & .752 & .775 & .770 \\
\hline
\end{tabular}

a.Dependent Variabel : Kepuasan Pasien

Sumber : Data primer yang telah di olah dengan IBM SPSS versi 17 for windows

a. Pengujian HipotesAnalisis I dengan Uji Parsial (uji t)

$\mathrm{H} 0: \mathrm{b} 1=0$ Tidak ada pengaruh positif signifikan variabel Bangunan terhadap kepuasan pasien pada puskesmas Rawabuntu

$\mathrm{H} 1: b 1 \neq 0$ Ada pengaruh positif signifikan variabel Bangunan terhadap kepuasan pasien pada puskesmas Rawabuntu

Dari tabel diatas dapat dilihat bahwa variabel variabel Bangunan diperoleh $t_{\text {hitung }} 2,632$ dengan signifikansi t sebesar 0,001 lebih besar dari $t_{\text {tabel }}=1,6652(2,632>1,6652)$, atau signifikansi $t$ lebih kecil dari 0,05 
$(0,001<0,05)$, sesuai dengan kriteria yaitu: Jika $t_{\text {hitung }} \geq t_{\text {tabel, }}(\alpha, d k)$, atau signifikansi t lebih kecil dari 0,05, berarti HO ditolak dan H2 diterima, hal ini menunjukkan bahwa Variabel Bangunan berpengaruh positif dan siginifikan terhadap Kepuasan Pasien pada Puskesmas Rawabuntu.

b. Pengujian Hipotesis II dengan Uji Parsial (Uji t)

$\mathrm{H} 0: \mathrm{b} 2=0$ Tidak ada pengaruh positif signifikan variabel Peralatan terhadap kepuasan pasien pada Puskesmas Rawabuntu

$\mathrm{H} 2: \mathrm{b} 2 \neq 0$ Ada pengaruh positif signifikan variabel Peralatan terhadap kepuasan pasien pada Puskesmas Rawabuntu

Dari tabel diatas dapat dilihat bahwa variabel peralatan diperoleh

Dari tabel diatas dapat dilihat bahwa variabel variabel Peralatan diperoleh $t_{\text {hitung }} .1,746$ dengan signifikansi $t$ sebesar 0,045 lebih besar dari $t_{\text {tabel }}=1,663(1,746>1,663)$, atau signifikansi t lebih kecil dari $0,05(0,045<0,05)$, sesuai dengan kriteria yaitu: jika $t_{\text {hitung }} \geq$ $t_{\text {tabel, }}(\alpha, d k)$, atau signifikansi t lebih kecil dari 0,05, berarti HO ditolak dan $\mathbf{H 2}$ diterima, hal ini menunjukkan bahwa variabel Peralatan berpengaruh positif dan siginifikan terhadap Kepuasan pasien pada Puskesmas Rawabuntu.

c. Pengujian Hipotesis III dengan Uji Parsial (Uji t)

$\mathrm{H} 0: \mathrm{b} 3=0$ Tidak ada pengaruh positif signifikan variabel SDM terhadap kepuasan pasien pada Puskesmas Rawabuntu

H3:b3 $\neq 0$ Ada pengaruh positif signifikan variabel SDM terhadap kepuasan pasien pada Puskesmas Rawabuntu

Dari tabel diatas dapat dilihat bahwa variabel variabel SDM diperoleh $t_{\text {hitung }} .10,677$ dengan signifikansi t sebesar 0,000 lebih besar dari $t_{\text {tabel }}=1,663(1,746>1,663)$, atau signifikansi t lebih kecil dari 0,05 $(0,045<0,05)$, sesuai dengan kriteria yaitu: jika $t_{\text {hitung }} \geq t_{\text {tabel, }}(\alpha, d k)$, atau signifikansi t lebih kecil dari 0,05 , berarti $\mathbf{H 0}$ ditolak dan H3 diterima, hal ini menunjukkan bahwa variabel SDM berpengaruh positif dan siginifikan terhadap Kepuasan Pasien pada Puskesmas Rawabuntu.

d. Uji Hipotesis IV dengan Uji Simultan (Uji F)

$\mathrm{H0}: \mathrm{b} 1: \mathrm{b} 2: \mathrm{b} 3=0$ tidak ada pengaruh signifikan variabel Bangunan, Peralatan, dan SDM secara bersama-sama terhadap Kepuasan Pasien pada Puskesmas Rawabuntu.

$\mathrm{H} 4: \quad b 1: b 2: b 3 \neq 0$ Ada pengaruh signifikan variabel Bangunan, Peralatan, dan SDM secara bersama-sama terhadap Kepuasan Pasien pada Puskesmas Rawabuntu.

\section{Uji Hipotesis Simultan (Uji F)}

Untuk menguji pengaruh Bangunan, Peralatan, dan SDM secara bersama-sama terhadap Kepuasan Pasien pada Puskesmas Rawabuntu. Dapat digunakan dengan uji statistic F (Uji F). Dengan menggunakan taraf signifikansi $5 \%(0,05)$ dan derajat kebebasan (dk) dengan Rumus $\mathrm{dk}=\mathrm{n}-\mathrm{k}-1$, Membandingkan $\mathrm{F}_{\text {hitung }}$ dengan $\mathrm{F}_{\text {tabel }}$ dengan kriteria sbb:

Jika $\mathbf{F}_{\text {hitung }} \geq \mathrm{F}_{\text {tabel, }}(\mathbf{\alpha}, \mathrm{dk})$, berarti $\mathrm{H} 0$ ditolak dan $\mathrm{H} 1, \mathrm{H} 2, \mathrm{H} 3$ diterima. 
Jika $\mathbf{F}_{\text {hitung }}<\mathrm{F}_{\text {tabel }}(\alpha, \mathrm{dk})$, berarti $\mathrm{H} 0$ diterima dan $\mathrm{H} 1, \mathrm{H} 2 . \mathrm{H} 3$ ditolak.

Dimana derajat kebebasan (dk) adalah: $\mathrm{dk}=\mathrm{n}-\mathrm{k}-1$

$=55-3-1$

$=51$

$\mathrm{F}_{\text {tabel }}=\mathbf{F}(\mathrm{a} ; \mathrm{dk})$

$=0,05 ; 51$ )

Karena dalam tabel tidak ditemukan $\mathrm{dk}=51$ maka dicari melalui perhitungan interpolasi sebagai berikut:

Diketahui $F(0,05 ; 60)=3,01$

$\mathrm{F}(0,05 ; 60)=2,89$

Maka untuk $\mathrm{dk}=51$

$\frac{76-60}{120-76}=\frac{x-3,01}{2,89-x}$

$\frac{16}{44}=\frac{x-3,01}{2,89-x}$

$46,24-16 x=44 x-132,44$

$178,68=60 x$

$x=\frac{178,68}{60}$

$=2,978$

Didapat $x=1,663$ maka untuk $F_{\text {tabel }}(0,05 ; 96)$ adalah sebesar 2,978.

Adapun hasil uji $F$ dengan pengelolaan IBM SPSS versi 17 from window (2012) dapat dilihat pada tabel dibawah ini.

Tabel 4.12 Hasil Uji F ANOVA $^{\text {b }}$

\begin{tabular}{|l|c|c|c|c|c|}
\hline Model & Sum of Squares & $\mathrm{df}$ & Mean Square & $\mathrm{F}$ & Sig. \\
\hline $1 \quad$ Regression & 8.708 & 3 & 2.903 & 38.754 & $.000^{\mathrm{a}}$ \\
Residual & 5.692 & 76 & .075 & & \\
Total & 14.400 & 79 & & & \\
\hline
\end{tabular}

a. Predictors: (Constant), X3, X2, X1

b. Dependent Variable: $Y$

Sumber : Data Primer yang telah diolah dengan IBM SPSS versi 17 (2012).

Dari hasil uji anova pada tabel diatas diperoleh $\mathrm{F}_{\text {hitung }} 38,754$ dengan signifikansi $F$ sebesar 0,00 lebih besar dari $F_{\text {tabel }}=2,978(38,754>$ 2,978), atau signifikansi $F$ lebih kecil dari $0,05(0,00<0,05)$, sesuai dengan kriteria yaitu: Jika $F_{\text {hitung }} \geq F_{\text {tabel, }}(\alpha, d k)$, atau signifikansi $F<$ 0,05, berarti $\mathbf{H 0}$ ditolak dan $\mathbf{H 4}$ diterima, hal ini menunjukkan bahwa Variabel Bangunan, Peralatan, dan SDM secara bersama-sama berpengaruh positif dan siginifikan terhadap Kepuasan Pasien pada Puskesmas Rawabuntu. 


\section{Kesimpulan}

Dari hasil analisis data dan pembahasan pada bab sebelumnya dapat disimpulkan sebagai berikut:

1. Variabel Bangunan $\left(X_{1}\right)$ berpengaruh positif terhadap Kepuasan Pasien (Y) dengan nilai koefisien sebesar 0,088. Yang artinya jika variabel Bangunan $\left(X_{1}\right)$ meningkat satu satuan dengan asumsi variabel Peralatan $\left(\mathrm{X}_{2}\right)$ dan variabel SDM $\left(\mathrm{X}_{3}\right)$ tetap, maka Kepuasan Pasien akan meningkat sebesar 0,088 .

2. Variabel Peralatan $\left(\mathrm{X}_{2}\right)$ berpengaruh positif terhadap Kepuasan Pasien $(\mathrm{Y})$ dengan nilai koefisien sebesar 0,073 . Yang artinya jika variabel Peralatan $\left(X_{2}\right)$ meningkat satu satuan dengan asumsi variabel Bangunan $\left(X_{1}\right)$ dan variabel SDM $\left(\mathrm{X}_{3}\right)$ tetap, maka Kepuasan Pasien ( $\mathrm{Y}$ ) akan meningkat sebesar 0,073 .

3. Variabel SDM $\left(X_{3}\right)$ berpengaruh positif terhadap Kepuasan Pasien ( $Y$ ) dengan nilai koefisien sebesar 0,859 . Yang artinya jika variabel SDM $\left(X_{3}\right)$ meningkat satu satuan dengan asumsi variabel Bangunan $\left(X_{1}\right)$ dan variabel Peralatan $\left(\mathrm{X}_{2}\right)$ tetap, maka Kepuasan Pasien $(\mathrm{Y})$ akan meningkat sebesar 0,859.

Dari ketiga variabel di atas dapat disimpulkan bahwa, jika faktor $\mathbf{X}_{1}$ dan $\mathbf{X}_{2}$ konstan, maka kenaikan satu satuan $\mathbf{X}_{\mathbf{3}}$ (variabel bebas SDM) akan meningkatkan $Y$ (Kepuasan Pasien) sebesar 0,859 satuan. Jika faktor $\mathbf{X}_{\mathbf{2}}$ \& $\mathbf{X}_{3}$ konstan, maka kenaikan satu satuan $\mathbf{X}_{\mathbf{1}}$ (variabel bebas bangunan) akan meningkatkan $Y$ (Kepuasan Pasien) sebesar 0,088 satuan. Jika faktor $\mathbf{X}_{\mathbf{1}}$ dan $\mathbf{X}_{\mathbf{3}}$ konstan, maka kenaikan satu satuan $\mathbf{X}_{\mathbf{2}}$ (variabel Peralatan) akan meningkatkan $Y$ (Kepuasan Pasien) sebesar 0,073 satuan.

4. Faktor bangunan, peralatan, dan SDM, secara bersama-sama mempunyai pengaruh positif yang signifikan terhadap kepuasan pasien pada Puskesmas Rawabuntu. Dari tabel diatas dapat dilihat bahwa nilai $\mathrm{R}$ Square sebesar 0,495 atau 49,5 \%. Hal ini dapat dijelaskan bahwa bangunan, peralatan dan sumber daya manusia secara bersama-sama berpengaruh terhadap Kepuasan pasien pada Puskesmas Rawabuntu yaitu sebesar $49,5 \%$. Sisanya $50,5 \%$ dipengaruhi oleh faktor lain yang tidak diteliti. Dalam hal ini adalah lokasi keberadaan Puskesmas yang kurang strategis, Motivasi pengabdian pegawai yang masih kurang optimal, dan insentif atau kompensasi pegawai yang relatif rendah. Model regresi berganda yang diperoleh adalah $Y=0,025+0,088 X 1+0,073$ X2 + 0,0859 X3.

\section{Saran}

Berdasarkan kesimpulan yang telah dipaparkan diatas, berikut adalah saran-saran yang dapat dilaksanakan oleh Puskesmas Rawabuntu:

1. Puskesmas Rawabuntu perlu meningkatkan fasilitas bangunan sesuai peraturan perundang-undang dinkes yang berlaku sehingga menghasilkan pelayanan yang lebih maksimal.

2. Puskesmas Rawabuntu perlu memperbaiki dan meningkatkan peralatan yang ada sesuai standar yang di tetapkan oleh menteri kesehatan yang berlaku, sehingga pasien tidak ragu dengan peralatan medis yang tersedia

3. Puskesmas Rawabuntu perlu meningkatkan kwalitas tenaga medis dan sumber daya manusia melalui diklat, seminar, dan pelatihan-pelatihan yang berkaitan dengan program pelayanan masyarakat secara berkala. 
Puskesmas Rawabuntu perlu meningkatkan usaha dalam meningkatkan pelayanan yang lebih optimal dan terpadu agar dapat meningkatkan tingkat kepuasan pasien serta meningkatkan jumlah pengunjung baru yang berobat di Puskesmas Rawabuntu.

\section{G. DAFTAR PUSTAKA}

Arikunto, S. 2002. Prosedur Suatu Penelitian: Pendekatan Praktek. Edisi Revisi Cooper \& Emory. 1995. Metode Penelitian Bisnis. Jilid I. Edisi Kelima. Jakarta. Penerbit : Erlangga.

Dudy Wiyancoko (2007), Manajemen Pemasaran Penerbit KPG (kepustakaan Populer Gramedia).

Ghozali, Imam, 2003, Analisis Multi Variant dengan Program SPSS, Badan Penerbit Universitas Diponegoro, Semarang.

Kamus Besar Bahasa Indonesia, yang dibuat oleh Departemen Pendidikan dan Kebudayaan, Terbitan Balai Pustaka, Jakarta, Tahun 1990,

Kepmenpan No. Kep/25/M.Pan/2/2004 tentang Kepuasan Pelayanan Publik

Keputusan menteri pekerjaan umum nomor : 441/kpts/1998 tentang Persyaratan teknis bangunan dan gedung,

Keputusan Menteri Kesehatan R.I no. 116/SK/79: tentang Umur perlatan medis Kotler, Philip, 2007, Manajemen Pemasaran, Edisi Kedua belas, Indeks, Jakarta. Moh. Nazir, 2003, Metode Penelitian, Cetakan Kelima, Jakarta, Ghalia Indonesia. Peraturan Menteri Kesehatan RI. No. 220/Men.Kes/Per/Ix/1976 tertanggal 6 September 1976, yang dimaksud dengan: Alat Kesehatan (ALKES)

Sugiono. 2004. Statistika Untuk Penelitian. Cetakan Keenam. Penerbit Alfabeta. Bandung.

Sugiono dan Wibowo. 2002. Statistik Penelitian Edisi I. Penerbit Alfabeta. Bandung.

Supranto (1999) Alat Ukur dikatakan Reliable

Maslow \& Siagian, (1981), Menyebutkan 5 tingkatan Kebutuhan Manusia, yang secara umum dapat dijelaskan

Manullang (1980), Tujuan Pengembangan Pegawai sebenarnya sama dengan tujuan latihan Pegawai

UU No. 28 Tahun 2002 "tentang Bangunan Gedung" Pasal 1 Poin 1 dijelskan bahwa "Bangunan Gedung".

Umar, Husein, 2005, Riset Pemasaran dan Perilaku Konsumen, Cetakan Keempat, Gramedia Pustaka Utama, Jakarta.

William J. Stanton (Basu Swasta, 1984) Manajemen pemasaran penerbit Gramedia Jakarta. 